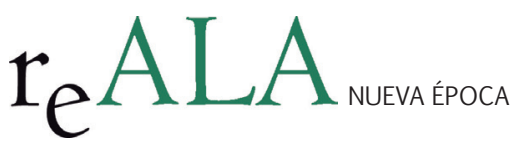

REALA, n 3, enero-junio 2015 ISSN: 1989-8975

DOI: http://dx.doi.org/10.24965/reala.voi3.10244

\title{
La función de la legislación básica en la determinación de las competencias municipales
}

\author{
Joaquín Alonso Varo \\ Secretario del Ayuntamiento de Aguilar de la Frontera, Córdoba \\ jalonsovaro@hotmail.com
}

Resumen

El presente trabajo trata de esclarecer el sistema de atribución de las competencias municipales. Para ello parte del concepto de autonomía local haciendo hincapié en su aspecto competencial, delimitando las funciones que al respecto corresponden al legislador básico y al legislador sectorial. Estudia particularmente el artículo 25.2 de la LBRL delimitando su función en el ordenamiento jurídico.

Bajo el epígrafe "Ia crisis del sistema" analiza diversos pronunciamientos judiciales y novedades legislativas (SSTC 31/2012, 240/2006 y LRSAL) que parecen alterar el sistema de atribución de competencias.

Asimismo estudia las Disposiciones Transitorias $1^{a}, 2^{a}$ y $3^{a}$ de la LRSAL y defiende la posibilidad de que el legislador básico pueda delimitar negativamente el ámbito competencial de la autonomía local, impidiendo al legislador sectorial atribuir competencias a los municipios en determinadas materias.

Termina proponiendo un sistema que garantice la adecuación de las obras y servicios municipales a las necesidades sociales.

Palabras clave

Autonomía local, legislador básico, competencias locales.

\section{The function of the basic legislation in determining municipal} powers

\footnotetext{
Abstract

The aim of this document is to clarify the system to assign the town hall governments' competences. To achieve it, the argument line foundations are underpinned in the local autonomy concept, stressing on its competence aspect. Furthermore, the roles' allocation among overall and specific issues lawmakers is defined in this section. Later, this paper came focused on the article 25.2 of the LBRL, outlining its role concerning the legal system.

In the chapter titled "the system's crisis" this essay studies several judgement assessments along with the legal system novelties (SSTC 31/0212, 240/2006 and LRSAL) which seem to change the competences allocation system.

Likewise, this paper embraces the examination of the transitional legal regulations and concurs the thesis regarding with the capability of the overall lawmaker to restrict the local government competence scope, rejecting to the specific issues lawmaker capability for empowering to the town hall government to rule regarding certain matters.

To come to an end, this paper suggests a method to guarantee that works and local facilities match with the social necessities.
}

Keywords

Local autonomy, overall lawmaker, town hall government's competences. 
1.- INTRODUCCIÓN. 2.- LAS COMPETENCIAS MUNICIPALES EN LA CONSTITUCION: LA GARANTIA INSTITUCIONAL DE LA AUTONOMÍA LOCAL. 3.- LAS COMPETENCIAS MUNICIPALES EN LA LBRL ANTERIOR A LA LRSAL. 4.- ESTUDIO DEL ARTÍCULO 25.2 DE LA LBRL EN SU REDACCION ANTERIOR A LA LRSAL. 5.- LA CRISIS DEL SISTEMA. 6.- DISPOSICIONES TRANSITORIAS PRIMERA, SEGUNDA Y TERCERA DE LA LRSAL. DELIMITACION NEGATIVA DE LA AUTONOMIA LOCAL. 7.- BREVE VALORACION DE LA LRSAL Y PROPUESTAS DE REFORMA.

\section{1.- INTRODUCCION}

La entrada en vigor de la Ley 27/2013, de 27 de diciembre, de racionalización y sostenibilidad de la Administración Local (en adelante LRSAL) ha producido un considerable revuelo entre los operadores jurídicos locales (o al menos entre un amplio sector de los mismos), que, desde mi punto de vista de forma exagerada, han considerado que dicha norma suponía una modificación, no sólo de aspectos concretos, sino de la misma esencia de la Ley 7/1985, de 2 de abril, Reguladora de las Bases del Régimen Local (en adelante LBRL), afectando a los principios generales que desde la entrada en vigor de la misma informan el régimen jurídico local español.

Como he adelantado dicha opinión me parece exagerada ya que una adecuada interpretación y aplicación de la LRSAL exige que previamente se determine la naturaleza de la misma, la cual puede caracterizarse por las siguientes notas':

1.- La LRSAL es una una ley de reforma. Efectivamente la LRSAL es, básicamente, una reforma de la LBRL (con independencia de que modifique en menor medida otras leyes de ámbito local), y no una nueva ley básica de régimen local.

Recordemos que el último gran intento de reforma del régimen local español, en concreto el realizado entre los años 2004 a 2007 por el gobierno socialista de José Luis Rodríguez Zapatero, siendo Ministro de Administraciones Públicas Jordi Sevilla Segura y Director General de Cooperación Local Manuel Zafra Victor, si pretendía la derogación de la LBRL y su sustitución por un nuevo texto articulado: la no nacida Ley Básica del Gobierno y de la Administración Local².

2.- La LRSAL no modifica la estructura y los principios generales de la LBRL, sino que se limita a introducir en la misma una serie de modificaciones puntuales (algunas de gran calado), conservando las notas esenciales del régimen vigente.

En este sentido y refiriéndonos específicamente al tema competencial, podemos observar una identidad sustancial entre la regulación contenida en la LBRL antes y después de la LRSAL, así:

a) La LBRL anterior al 31 de diciembre de 2013 establecía en su artículo 7.1 que "las competencias de las entidades locales son propias o atribuidas por delegación”. Al margen de ello el artículo 28 de la LBRL establecía la posibilidad de que los municipios actuaran más allá del círculo de sus competencias, al otorgarles la posibilidad de "realizar actividades complementarias de las propias de otras administraciones públicas, /.../."

b) El artículo 7.1 no resulta modificado por la LRSAL por lo que las entidades locales siguen teniendo competencias propias y atribuidas por delegación. Es cierto que la LRSAL deroga el artículo 28 de la LBRL, pero la función que el mismo desempeñaba (habilitar la actividad de los municipios más allá de su ámbito competencial) es asumido ahora por el artículo 7.4 de la LBRL, que permite a las entidades locales "ejercer competencias distintas de las propias y de las atribuidas por delegación cuando no se ponga en riesgo la sostenibilidad financiera del conjunto de la Hacienda municipal, /.../ y no se incurra en un supuesto de ejecución simultánea del mismo servicio público con otra Administración Pública."

En resumen antes y después de la LRSAL los municipios tienen competencias propias y delegadas, y están habilitados para actuar más allá de dichas competencias, antes vía artículo 28 y actualmente vía artículo 7.4 de la LBRL. Es cierto que existen matices diferenciadores que después analizaremos, pero en esencia todo sigue igual.

3.- La finalidad de la LRSAL es introducir criterios de racionalidad, eficacia y eficiencia en el gasto público local, por lo que en mi opinión dicha ley es, o pretende ser, el desarrollo en el sector local del artículo 31.2 de la Constitución (El gasto público realizará una asignación equitativa de los recursos públicos, y su programación y ejecución responderán a los criterios de eficiencia y economía).

\footnotetext{
En relación con el significado de la reforma puede consultarse la "Nota explicativa de la Reforma Local”.
}

Para profundizar en dicha reforma ver "Libro Blanco para la reforma del Gobierno Local” (2005). 
Para conseguir este objetivo la ley pretende, y así resulta desde el primer párrafo de su preámbulo, garantizar el cumplimiento del objetivo de estabilidad presupuestaria, consagrado por el artículo 135 de la Constitución como principio rector que debe presidir las actuaciones de todas las Administraciones Públicas, y clarificar las competencias municipales haciendo efectivo el principio "una administración una competencia”.

Si observamos las modificaciones introducidas por la LRSAL en materia competencial se observa claramente lo que acabamos de exponer, así:

a) El artículo 2.1 de la LBRL, que establecía que la atribución de competencias a las entidades locales se realizaría de "conformidad con los principios de descentralización y de máxima proximidad de la gestión administrativa a los ciudadanos", se modifica para decirnos que dicha atribución debe realizarse "de conformidad con los principios de descentralización, proximidad, eficacia y eficiencia, y con estricta sujeción a la normativa de estabilidad presupuestaria y sostenibilidad financiera." (las negritas son mías).

b) En materia de competencias propias el artículo 25 de la LBRL pasa a decirnos que las Leyes que atribuyan dichas competencias:

1. deberán evaluar la conveniencia de la implantación de servicios locales conforme a los principios de descentralización, eficiencia, estabilidad y sostenibilidad financiera (apartado $3^{\circ}$ ),

2. deberán ir acompañadas de una memoria económica que refleje ... el cumplimiento de los principios de estabilidad, sostenibilidad financiera y eficiencia del servicio o la actividad (apartado $4^{\circ}$ ), y

3. garantizarán que no se produce una atribución simultánea de la misma competencia a otra Administración Pública (apartado $5^{\circ}$ ).

c) En materia de competencias delegadas se exige, entre otras cosas, que:

- La delegación mejore la eficiencia de la gestión pública, contribuya a eliminar duplicidades administrativas y sea acorde con la legislación de estabilidad presupuestaria y sostenibilidad financiera, para lo cual deberá acompañarse de una memoria económica que así lo justifique (artículo 27.1 párrafos 2 y 4 de la LBRL).

- La delegación habrá de ir acompañada en todo caso de la correspondiente financiación (artículo 27.6 de la LBRL).

d) En cuanto al ejercicio de competencias distintas de las propias o de las atribuidas por delegación aparece condicionado en el artículo 7.4 de la LBRL a que no se ponga en riesgo la sostenibilidad financiera del conjunto de la Hacienda municipal, de acuerdo con los requerimientos de la legislación de estabilidad presupuestaria y sostenibilidad financiera y no se incurra en un supuesto de ejecución simultánea del mismo servicio público con otra Administración Pública. A estos efectos, serán necesarios y vinculantes los informes previos de la Administración competente por razón de materia, en el que se señale la inexistencia de duplicidades, y de la Administración que tenga atribuida la tutela financiera sobre la sostenibilidad financiera de las nuevas competencias.

4.- Si nos encontramos ante una ley de reforma que respeta la estructura y los principios generales hasta ahora vigentes, limitándose a introducir modificaciones puntuales con una finalidad concreta, podemos concluir que los criterios que nos venían sirviendo para interpretar y aplicar la LBRL en su versión anterior a la LRSAL, nos seguirán sirviendo después de la reforma.

Por lo tanto la jurisprudencia, fundamentalmente del Tribunal Constitucional (en adelante TC) y del Tribunal Supremo (en adelante TS), relativa a la materia que vamos a tratar sigue plenamente vigente, por lo que debe constituir nuestro punto de partida de cara a una correcta interpretación y aplicación del régimen competencial regulado por la LBRL tras la entrada en vigor de la LRSAL.

\section{2.- LAS COMPETENCIAS MUNICIPALES EN LA CONSTITUCION: LA GARANTIA INSTITUCIONAL DE LA AUTONOMÍA LOCAL.}

Por todos es sabido que la Constitución Española (en adelante CE), a diferencia de lo que ocurre con el Estado y las Comunidades Autónomas, no contiene una regulación de las competencias locales.

Dicha ausencia de regulación supone que, con carácter general, la atribución de competencias a los municipios corresponde al legislador ordinario (ya sea estatal o autonómico) según la distribución constitucional de competencias, sin más limitación que el respeto a la autonomía local constitucionalmente garantizada, lo que obliga a plantearnos en que consiste dicha autonomía local. 
Es sabido que el TC desde la Sentencia de 32/1981 viene configurando la autonomía local como garantía institucional ${ }^{3}$, al decirnos en el primer párrafo del Fundamento Jurídico $3^{\circ}$ que (las negritas son mías):

"El orden jurídico-político establecido por la Constitución asegura la existencia de determinadas instituciones, a las que se considera como componentes esenciales y cuya preservación se juzga indispensable para asegurar los principios constitucionales, estableciendo en ellas un núcleo o reducto indisponible por el legislador. Las instituciones garantizadas son elementos arquitecturales indispensables del orden constitucional y las normaciones que las protegen son, sin duda, normaciones organizativas, pero a diferencia de lo que sucede con las instituciones supremas del Estado, cuya regulación orgánica se hace en el propio texto constitucional, en éstas la configuración institucional concreta se defiere al legislador ordinario, al que no se fija más límite que el del reducto indisponible o núcleo esencial de la institución que la Constitución garantiza. Por definición, en consecuencia, la garantía institucional no asegura un contenido concreto o un ámbito competencial determinado y fijado de una vez por todas, sino la preservación de una institución en términos recognoscibles para la imagen que de la misma tiene la conciencia social en cada tiempo y lugar. Dicha garantía es desconocida cuando la institución es limitada, de tal modo que se la priva prácticamente de sus posibilidades de existencia real como institución para convertirse en un simple nombre. Tales son los límites para su determinación por las normas que la regulan y por la aplicación que se haga de éstas. En definitiva, la única interdicción claramente discernible es la de la ruptura clara y neta con esa imagen comúnmente aceptada de la institución que, en cuanto formación jurídica, viene determinada en buena parte por las normas que en cada momento la regulan y la aplicación que de las mismas se hace."

Desde dicho momento la autonomía local, y su garantía institucional, junto a innegables aspectos organizativos y de funcionamiento, ha presentado una evidente "vertiente competencial", ya que, aunque no garantiza un "ámbito competencial determinado", si exige la regulación de la provincia y el municipio en términos reconocibles para la conciencia social en cada tiempo y lugar, lo que supone que el legislador ordinario debe atribuir a los entes locales aquellas competencias que, a los ojos de la sociedad, identifiquen la institución como tal, vulnerando dicho principio si la regulación de dichas instituciones rompe, de forma clara y nítida, con la imagen comúnmente aceptada de la institución por la conciencia social en cada tiempo y lugar.

Este concepto de la autonomía local, que excede de lo meramente jurídico y se adentra en el campo de la sociología, nos obliga a determinar, en cada momento histórico, que entiende la sociedad por municipio y a trasladar dicha consideración al ordenamiento jurídico.

Esta determinación, y su posterior concreción jurídica, plantea multitud de problemas, si bien, a mi juicio, hay dos que presentan un mayor calado: por un lado quien es el encargado de realizarla y por otro el contenido de la misma.

Analicemos ambos aspectos, comenzando por la determinación del legislador a quien corresponde concretar el principio de autonomía local constitucionalmente garantizada.

La Constitución Española contiene un reconocimiento explícito de la autonomía local (artículos 137 y 140), consagra a los municipios y a las provincias como organizaciones territoriales básicas (artículo 137), determina las instituciones (Ayuntamientos y Diputaciones Provinciales) a las que corresponde el gobierno de dichas entidades (artículos 140 y 141) y garantiza la suficiencia financiera de las Haciendas Locales (artículo 142). Sin embargo no entra a regular el ámbito competencial reservado a las entidades locales, limitándose en el artículo 137 a vincular la autonomía local con la gestión de sus intereses.

Por lo tanto si la Constitución no concreta el ámbito competencial exigido por la autonomía local, dicha concreción corresponderá al legislador ordinario, planteándose, desde la misma publicación de la LBRL, si dicha determinación correspondía directamente al legislador sectorial (estatal o autonómico) que no tendría más limitación en dicha función que la derivada directamente de la Constitución, o si, por el contrario, corresponde al legislador estatal básico establecer unos criterios o directrices, vinculantes para el legislador sectorial, que concreten el contenido competencial mínimo garantizado por la autonomía local.

Dicha cuestión fue determinante en el recurso de inconstitucionalidad planteado por la Generalidad de Cataluña contra la LBRL, al considerar dicha Comunidad Autónoma que la habilitación que el artículo 149.1.18 de la

3 En relación al concepto de “garantía institucional de la autonomía local”, García Roca, Javier en su artículo “El concepto actual de autonomía local según el bloque de constitucionalidad” (2000), nos dice (páginas 35 y 36), "Por el contrario tanto Aja, como García Morillo o yo mismo hemos preferido hablar de "garantía constitucional de la autonomía local” antes que de "garantía institucional". Un concepto distinto y más amplio..." 
C.E. otorga al legislador estatal para regular las bases de la Administración Local, alcanza exclusivamente aspectos organizativos y de funcionamiento, pero no competenciales, cuya determinación debería quedar íntegramente en manos del legislador competente por razón de la materia, ya que lo contrario supondría que el legislador estatal habría "asumido el papel de constituyente, al interpretar que a él le corresponde instrumentar la garantía institucional de los Entes locales, sin que pueda encontrarse correspondencia entre el objeto de esa garantía y el de la competencia que al Estado le reserva el artículo 149.1.18. a de la Constitución." (Fundamento jurídico $1^{\circ}$ STC 214/1989)

EI TC, por el contrario, consideró en la Sentencia 214/1989 relativa a LBRL, que el artículo 148.1.18 de la C.E. habilita al legislador básico para regular cuestiones competenciales de cara a garantizar la autonomía local constitucionalmente reconocida, y así nos dice en el fundamento jurídico $1^{\circ}$ (las negritas son mías):

"El razonamiento, en concreto, de este Tribunal es el siguiente: "Como titulares de un derecho de autonomía constitucional garantizada, las Comunidades locales no pueden ser dejadas en lo que toca a la definición de sus competencias y la configuración de sus órganos de gobierno a la interpretación que cada Comunidad Autónoma pueda hacer de ese derecho, tanto más cuanto que el mismo no va acompañado, como en otros ordenamientos sucede, de un derecho de carácter reaccional que, eventualmente, les abra una vía ante la jurisdicción constitucional frente a las normas con rango de ley». Por todo ello, el Tribunal Constitucional deja sentado que la «garantía constitucional es de carácter general y configuradora de un modelo de Estado, y ello conduce, como consecuencia obligada, a entender que corresponde al mismo la fijación de principios o criterios básicos en materia de organización y competencia.

Pues bien, es esta doctrina -reiterada en posteriores sentencias: fundamentalmente SSTC 76/1983, de 5 Agosto (fundamento jurídico $19^{\circ}$ ) y 27/1987, de 27 Febrero (fundamento jurídico $2^{\circ}$ )-, según la cual debe ser el legislador estatal, con carácter general y para todo tipo de materias, el que fije unos principios o bases relativos a los aspectos institucionales (organizativos y funcionales) y a las competencias locales, encontrando cobertura a esa encomienda estatal en el concepto mismo de "bases del régimen jurídico de las Administraciones Públicas", por cuanto dicha expresión engloba a las Administraciones Locales SSTC 25/1983, fundamento jurídico $4^{\circ} ; 76 / 1983$, fundamento jurídico $38^{\circ} ; 99 / 1987$, fundamento jurídico $2^{\circ}$ b), la que, con carácter general, inspira el sistema que articula la L.B.R.L...."

Por lo tanto reconocida por el TC la competencia del legislador estatal básico para establecer unos principios o bases relativos a las competencias locales con el objeto de garantizar la autonomía local, debemos abordar la segunda de las cuestiones mencionadas: el alcance de dicha habilitación.

Como hemos visto la STC 32/1981, al fijar la doctrina relativa a la garantía institucional de la autonomía local, nos dice que ésta garantiza:

1.- Un núcleo o reducto indisponible por el legislador.

2.- La preservación de una institución en términos recognoscibles para la imagen que de la misma tiene la conciencia social en cada tiempo y lugar.

También afirma que, por el contrario, la garantía institucional de la autonomía local no garantiza un ámbito competencial determinado y fijado de una vez por todas.

Estas cuestiones son esenciales para determinar cual será la función del legislador básico a la hora de establecer los criterios generales en materia de competencias locales, dado que, como hemos visto, la habilitación del legislador estatal para afrontar dicha tarea se enlaza con la consideración de que las entidades locales, como titulares de un derecho de autonomía constitucional garantizada, no pueden ser dejadas en lo que toca a la definición de sus competencias a la interpretación que cada Comunidad Autónoma pueda hacer de ese derecho.

Por lo tanto si la habilitación del legislador estatal para fijar unos criterios básicos en materia de competencias locales tiene por objeto garantizar la autonomía local, resulta fundamental saber a que se refiere el TC cuando, ya en la Sentencia 32/1981, nos dice que la autonomía local garantiza un "núcleo o reducto indisponible por el legislador" o la "preservación de una institución en términos recognoscibles".

Con la primera de las expresiones “núcleo o reducto indisponible por el legislador”, el TC parece referirse al mínimo competencial que en todo caso deben ostentar las corporaciones locales de cara a la gestión de sus respectivos intereses (artículo 137 y 140 de la CE). En este sentido la STC 214/1989 nos dice (las negritas son mías): 
“El legislador estatal, en el precepto impugnado, no ha hecho sino fijar ese mínimo competencial que, en todo caso, debe corresponder a los municipios en virtud de la propia garantía institucional de que gozan. Ese mínimo queda concretado en la competencia para prestar los servicios que enumera el artículo 26 de la Ley - previsión cuya constitucionalidad no ha sido cuestionada-- y en la garantía, formulada negativamente, de que no pueden quedar privados de toda intervención en cada una de las materias enumeradas en el apartado 2 del artículo 25."

Esta idea del "núcleo o reducto indisponible" como "mínimo competencial” se repite de forma constante en la jurisprudencia constitucional. Así las SSTC 37/2014, 121/2012 o 240/2006 nos dicen:

“El canon que este Tribunal deberá aplicar para resolver los conflictos en defensa de la autonomía local promovidos frente a leyes estatales se ciñe a los preceptos constitucionales (arts. 137, 140 y 141 CE) que establecen ese ‘contenido mínimo' que protege la garantía institucional y que hemos considerado definitorios de 'Ios elementos esenciales' o del 'núcleo primario' del autogobierno de los entes locales territoriales"

Por su parte las SSTC 121/2012, 51/2004 y 159/2001 nos dicen:

"So pena de incurrir en inconstitucionalidad por vulneración de la garantía institucional de la autonomía local, el legislador tiene vedada toda regulación de la capacidad decisoria de los entes locales respecto de las materias de su interés que se sitúe por debajo de ese umbral mínimo que les garantiza su participación efectiva en los asuntos que les atañen y, por consiguiente, su existencia como reales instituciones de autogobierno"

Por lo tanto de lo expuesto hasta el momento podemos extraer la siguiente CONCLUSION: Corresponde al legislador estatal básico establecer unos principios o bases en relación al mínimo competencial que, en todo caso, debe corresponder a los municipios en virtud de la garantía institucional de que gozan.

Como lógico corolario de lo anterior, dichos principios han de tener carácter vinculante para el legislador sectorial (estatal o autonómico) ${ }^{4}$, ya que de otra forma dicha regulación carecería de eficacia. En ese sentido la STC 214/1989 nos dice (las negritas son mías):

“... no se desciende a la fijación detallada de tales competencias, pues el propio Estado no dispone de todas ellas. De ahí que esa ulterior operación quede deferida al legislador competente por razón de la materia. Legislador, no obstante, que en el caso de las Comunidades Autónomas, no puede, con ocasión de esa concreción competencial, desconocer los criterios generales que los arts. 2.1. , 25.2. ${ }^{\circ}, 26$ y 36 de la misma L.R.B.R.L. han establecido." (fundamento jurídico $3^{\circ}$ ).

“/.../ especificando en el listado de materias sobre las que los municipios deben, en todo caso, ejercer competencias, las relativas a vivienda, educación, cultura, protección del medio ambiente, sanidad y prestación de servicios sociales y de promoción y reinserción social [art. 25.2., $\mathrm{d}$ ), n), m), f), h), i), k)]. La correlación de materias es, por tanto, evidente, si bien este art. 28 se configura como una cláusula competencial genérica que, más allá de las competencias que por imperativo de los arts. 2.1. y 25 de la Ley, el legislador sectorial debe reconocer a las entidades municipales, habilita a los municipios para que puedan desarrollar actividades complementarías de las propias de otras Administraciones. /.../" (fundamento jurídico $12^{\circ}$ ).

Ahora bien, dado que la ley estatal que establece dichos principios generales es una ley ordinaria (LBRL), el carácter vinculante de los mismos en relación a la legislación sectorial (estatal y autonómica) supone que una ley ordinaria estatal vincula a otras leyes posteriores del mismo Estado o de las CC.AA. Para justificar jurídicamente la vinculación del legislador sectorial a las directrices de la LBRL, el TC no ha dudado en afirmar que ésta, al menos cuando concreta principios constitucionales (entre los que se encuentra la autonomía local), forma parte del "bloque de constitucionalidad".

4 Sobre la vinculación del legislador sectorial ver García Roca, Javier (2000), apartado B.2 "Sobre el alcance de la configuración constitucional: La Constitución no define la autonomía local, pero prefigura un ámbito público de actuación ligado al interés local (art. 137) y el bloque de constitucionalidad lo concreta. No existe una libertad absoluta del legislador sectorial ya sea estatal o autonómico". 
En este sentido la Sentencia del TC 159/2001 nos dice (las negritas son mías):

"Por ello, únicamente teniendo en cuenta esta doble función y este doble contenido de la LBRL alcanza su pleno sentido lo que hemos dicho en otras ocasiones: que se trata de una ley que, por definir o delimitar las competencias estatales y autonómicas, y por actuar los valores superiores consagrados en el art. 137 CE, "tiene una singular y específica naturaleza y posición en el Ordenamiento jurídico" (STC 259/1988, de 22 de diciembre, FJ 2), integrándose sin dificultad, en aquella parte que sea concreción de principios constitucionales, dentro del llamado "bloque de la constitucionalidad" (art. 28.1 LOTC), según dijimos, entre otras, en las SSTC 27/1987, de 27 de febrero, FJ 5, y 109/1998, de 26 de mayo, FFJJ 5 y $12 . "$

\section{3.- LAS COMPETENCIAS MUNICIPALES EN LA LBRL ANTERIOR A LA LRSAL}

Como hemos visto la Constitución Española no regula las competencias municipales, quedando su determinación deferida al legislador ordinario competente por razón de la materia, el cual debe respetar el mínimo competencial que, en todo caso, corresponde a los municipios en virtud de la garantía institucional de que gozan, reconociéndose al legislador estatal la competencia para establecer, en base al artículo 149.1.18 de la Constitución, unos principios o bases, vinculantes para el legislador sectorial, en relación a dicho mínimo competencial.

La LBRL se asienta plenamente en dicho esquema.

En dicha ley el legislador estatal básico articula un sistema que pretende garantizar el mínimo competencial que ha de corresponder a los municipios como titulares de un derecho de autonomía constitucionalmente garantizado, mediante el juego combinado de, básicamente, los artículos 2, 4.1, 25 y 26.1 de la LBRL.

Una correcta interpretación de dichos artículos debe partir de la finalidad y objeto de los mismos, que no es la determinación de las competencias municipales, al menos de una forma global, sino garantizar el mínimo competencial que debe corresponder a los municipios como titulares de un derecho de autonomía constitucionalmente garantizado.

Quiere ello decir que la determinación de las competencias municipales corresponde, en todo caso, al legislador sectorial competente por razón de la materia, el cual, eso si, no goza de libertad absoluta en dicha tarea, sino que está obligado, en virtud de la determinación del mínimo competencial garantizado por la autonomía local llevada a cabo por el legislador básico, a atribuir competencias a los municipios en las materias del artículo 25.2 de la LBRL de conformidad con los principios del artículo 2 de la misma ley.

Sin embargo, la LBRL no prohíbe que el legislador sectorial atribuya a los municipios competencias en materias no incluidas en el artículo 25.2, ya que la función de dicho artículo es garantizar el mínimo de competencias que corresponde a los municipios en función de la autonomía que la constitución les garantiza, pero, en ningún caso, determinar el techo competencial de dichos entes (cuestión distinta es si el legislador básico estaría habilitado para ello, tema que trataremos más adelante), pudiéndose concluir, de forma gráfica, que la autonomía local tiene suelo pero no tiene techo.

Conforme a lo anterior no puede afirmarse, al menos con carácter general, que la LBRL establezca un sistema "bifásico" de atribución de competencias a los municipios, en el cual, en una primera fase, la ley básica establecería las materias en las que los municipios pueden ejercer competencias, para que, en una segunda fase, el legislador sectorial determinara las competencias concretas que han de ostentar dichos entes en cada una de aquellas. La aceptación de este esquema con carácter general supondría reconocer al artículo 25.2 de la LBRL el carácter de mínimo y máximo al mismo tiempo, lo que no se corresponde con la función de dicho artículo en nuestro ordenamiento jurídico.

No debemos extrapolar este sistema "bifásico", que efectivamente subyace en el artículo 25.2 de la LBRL, a la total determinación de las competencias municipales, sino reducirlo al ámbito que le es propio, y que no es otro que concretar (junto con los artículos anteriormente citados y particularmente el artículo 2 de la LBRL) el mínimo competencial que corresponde a los municipios en virtud de la autonomía de que gozan.

Por lo tanto podemos concluir que la determinación de las competencias municipales, conforme a la LBRL, corresponde al legislador sectorial competente por razón de la materia (sea estatal o autonómico), sobre el cual pesa lo que podíamos denominar una limitación o vinculación positiva, en el sentido de que se le impone un comportamiento positivo (atribuir competencias a los municipios en las materias del artículo 25.2 de la LBRL), sin que, por el contrario, pese sobre el mismo ninguna vinculación negativa, en el sentido de que no se le impone ninguna prohibición a la hora de atribuir competencias a los municipios en cualesquiera otras materias. 
Para referirse a lo que he denominado "limitación o vinculación positiva" la STC 214/1989, habla de "garantía formulada negativamente" haciendo hincapié en la prohibición que tiene el legislador sectorial de privar a los municipios de toda intervención en las materias enumeradas en el artículo 25.2, si bien considero que el artículo 25.2 de la LBRL, más que una abstención, lo que impone al legislador sectorial es un comportamiento positivo (conceder competencias en determinadas materias), si bien ambas posturas no son más que dos caras de la misma moneda.

El sistema establecido en la LBRL gozó desde el inicio de una valoración positiva por parte de nuestro TC, el cual en el fundamento jurídico $3^{\circ}$ de la Sentencia 214/1989 nos dice (las negritas son mías):

“3. En contestación a las alegaciones de los recurrentes, cabe decir que el art. 2 de la L.R.B.R.L. contiene dos previsiones bien diferenciadas, aunque dirigidas a idéntico fin. Fin que no es otro que el de concretar el alcance de la garantía constitucional de la autonomía local desde la perspectiva de las competencias locales. La Ley se ajusta así, en principio, a la propia doctrina constitucional, según la cual, "la garantía constitucional (de la autonomía local) es de carácter general y configuradora de un modelo de Estado", correspondiendo al Estado "la fijación de principios o criterios básicos en materia de organización y competencia” de las Entidades locales constitucionalmente necesarias."

a) A esta idea responde el párrafo $10^{\circ}$ del art. 2:

$$
\text { “... }
$$

Ningún reproche de inconstitucionalidad cabe formular a la referida previsión se condensa en la misma el criterio de que corresponde al legislador estatal la fijación de los principios básicos en orden a las competencias que deba reconocerse a las Entidades locales, estableciendo, y garantizando, al fin, "su derecho a intervenir en cuantos asuntos afecten directamente al circulo de sus intereses" y fijando al respecto unas directrices para llevar a cabo la asignación de tales competencias, directrices que se concretan en atender, en cada caso, a las características de la actividad pública y a la capacidad de gestión de la Entidad local, de acuerdo con los principios de descentralización y máxima proximidad de la gestión administrativa de los ciudadanos. Fijados esos criterios --que incuestionablemente se mueven en el plano de los principios generales y que, por ello mismo, no deben suscitar reparo alguno en orden a su reconocimiento como bases de la materia--, concreta algo más la L.R.B.R.L. al delimitar las materias en las que necesariamente, de acuerdo con los principios señalados, a las Entidades locales deberán atribuírseles competencias, e incluso, especificando para los municipios los servicios mínimos que, en todo caso, deberán prestar. Así se prevé para los municipios en los arts. $\mathbf{2 5 . 2}$ y 26, y para las provincias en el art. 36, sin que, por lo demás, tales previsiones hayan sido objeto de impugnación alguna.

Ahora bien, delimitada así la exigencia de orden competencial vinculada a la garantía constitucional de la autonomía de las entidades locales, la concreción última de las competencias locales queda remitida --y no podía ser de otra manera-- a la correspondiente legislación sectorial, ya sea estatal o autonómica, según el sistema constitucional de distribución de competencias entre el Estado y las Comunidades Autónomas.

Puede afirmarse, por tanto, que el sistema arbitrado por el párrafo $10^{\circ}$ del art. 2 de la L.R.B.R.L. resulta plenamente adecuado a la Constitución, sin que pueda apreciarse extralimitación alguna en la fijación de las bases relativas a las competencias locales. Se mantiene y conjuga, en efecto, un adecuado equilibrio en el ejercicio de la función constitucional encomendada al legislador estatal de garantizar los mínimos competenciales que dotan de contenido y efectividad a la garantía de la autonomía local, ya que no se desciende a la fijación detallada de tales competencias, pues el propio Estado no dispone de todas ellas. De ahí que esa ulterior operación quede deferida al legislador competente por razón de la materia." 
Dicha valoración positiva ${ }^{5}$ se ha mantenido a lo largo del tiempo, y así, entre otras podemos citar la STC 159/2001 que transcribe literalmente gran parte del fundamento 3 que acabamos de exponer.

\section{4.- ESTUDIO DEL ARTÍCULO 25.2 DE LA LBRL EN SU REDACCION ANTERIOR A LA LRSAL}

Dentro del conjunto de artículos que la LBRL dedica a garantizar la autonomía local en su vertiente competencial, el artículo 25.2 de la misma juega un papel central, en la medida en que viene a determinar aquellas materias en las que necesariamente los municipios han de ostentar competencias, de forma que todo aquello que no figure en el referido artículo no se encontraría amparado por la garantía institucional de la autonomía local, pudiendo el legislador sectorial decidir libremente si atribuye o no competencias a los municipios en dichas materias.

Ello convierte al artículo 25.2 de la LBRL en el principal garante de la autonomía local, lo que, a mi juicio, justifica un especial acercamiento al mismo.

A la hora de analizar el artículo 25.2 de la LBRL, considero que hay que partir de algunas ideas fundamentales que resultan de lo dicho hasta el momento:

1. El título que habilita al legislador estatal para dictar el artículo 25.2 de la LBRL es el artículo 149.1.18 de la Constitución.

2. El artículo 25.2 de la LBRL tiene como función concretar el mínimo competencial que la Constitución garantiza a los municipios en virtud de la autonomía local que les reconoce.

3. En la medida que el artículo 25.2 de la LBRL concreta principios constitucionales, forma parte del bloque de constitucionalidad (STC 159/2001).

4. Debido a lo anterior el artículo 25.2 de la LBRL resulta vinculante para el legislador sectorial estatal o autonómico.

5. La vinculación que el artículo 25.2 de la LBRL impone al legislador sectorial es de carácter positivo (le obliga a atribuir competencias a los municipios en determinadas materias) y no negativa (no impide la atribución de competencias en materias no incluidas en el mismo).

Por todo ello el artículo $\mathbf{2 5 . 2}$ no es un título directo de atribución de competencias, sino que se limita a señalar aquellas materias en las que el legislador sectorial (estatal o autonómico) competente por razón de la materia ha de reconocer competencias a los municipios, competencias que, por lo tanto, derivan de la legislación sectorial y no directamente del artículo 25.2 de la LBRL. En este sentido, y a efectos meramente dialécticos, podríamos decir que, aun reconociendo su carácter general y vinculante para todos los poderes públicos, el artículo 25.2 de la LBRL no es una norma dirigida a los municipios, sino al legislador sectorial respecto del cual constituye un mandato u obligación. Es por ello que las entidades locales no pueden apoyarse de forma directa en el artículo 25.2 de la LBRL para justificar su actividad, sino que habrán de buscar el título habilitante de la misma en la legislación sectorial. De esta forma, y aun a riesgo de exagerar, puede decirse que para el funcionamiento diario de los municipios el artículo 25.2 de la LBRL es indiferente. Cuando los municipios imponen una sanción en materia de tráfico, conceden una licencia de obras o autorizan la inhumación de un cadáver, no lo están haciendo porque las letras b), d) o j) del artículo 25.2 de la LBRL los autorice, sino porque los habilitan los pertinentes preceptos de la Ley sobre Tráfico, Circulación de Vehículos a Motor y Seguridad Vial, de la legislación autonómica en materia urbanística o del Reglamento de Policía Sanitaria Mortuoria que resulte de aplicación. En definitiva, si los municipios quieren saber que pueden o no pueden hacer (que eso en el fondo son las competencias) deben acudir a la legislación sectorial y no al artículo 25.2 de la LBRL.

La conclusión anterior se extrae con facilidad del párrafo inicial del artículo 25.2 de la LBRL que nos ha dicho siempre (antes y después de la LRSAL) que los municipios tienen competencias en los "términos de la legislación del Estado y de las Comunidades Autónomas" y de la interpretación que del mismo hace la jurisprudencia del TC.

Para terminar el análisis del artículo $\mathbf{2 5 . 2}$ en su redacción anterior a la LRSAL hay que decir que el mismo no establecía que las competencias municipales en las materias en él relacionadas hubieran de serlo con carácter de propias, lo que suponía que, teniendo en cuenta que el artículo 7 de la LBRL establecía que las competencias locales pueden ser propias o delegadas, el legislador sectorial cumplía el mandato del artículo 25.2 atribuyendo a los municipios exclusivamente competencias delegadas, o, dicho de otro modo, era posible que los municipios no tuvieran competencias propias en las materias de interés local enumeradas en el artículo 25.2 de la LBRL. En

5 Se muestra, por el contrario, crítico Javier García Roca (2000), que nos dice (página 69) "el artículo 25.2 [... ] se limita a fijar un elenco de materias y reenvía a la ley sectorial para determinar las competencias municipales sobre ellas (apartado $3^{\circ}$ ); técnica muy defectuosa que impide concretar el bloque de la constitucionalidad a efectos competenciales" 
este sentido la Ley $2 / 1988$, de 4 de abril, de Servicios Sociales de Andalucía unicamente atribuía a los municipios competencias delegadas, a pesar de que los servicios sociales estaban incluidos en el artículo 25.2 letra k) y que incluso el artículo 26 de la LBRL establecía que los servicios sociales constituían un servicio de prestación obligatoria en los municipios de más de 20.000 habitantes.

\section{5.- LA CRISIS DEL SISTEMA}

Recapitulando lo dicho hasta ahora el régimen competencial de los municipios establecido por la CE y por la LBRL se asentaba en los siguientes principios:

1.- La Constitución garantiza la autonomía de los municipios, que comprende tanto el aspecto organizativo y de funcionamiento como el competencial.

2.- El legislador básico es el encargado, con carácter exclusivo, de concretar el alcance de la autonomía local en materia competencial, ya que esta cuestión no puede dejarse a la interpretación que cada comunidad autónoma haga de este derecho.

3.- La normativa dictada al respecto por el legislador básico forma parte del bloque de constitucionalidad y por lo tanto vincula al legislador sectorial (estatal o autonómico).

4.- La autonomía local, reconocida en la Constitución y concretada en la legislación básica, garantiza un mínimo de competencias a los municipios, lo que se traduce en que el legislador sectorial está obligado a atribuir competencias a los municipios en las materias contenidas en el artículo 25.2 de la LBRL (vinculación positiva), pero no impide a dicho legislador sectorial atribuir competencias a los municipios en materias no contenidas en el referido artículo (ausencia de vinculación negativa).

Estos principios que venían siendo aceptados de forma prácticamente unánime desde la entrada en vigor de la LBRL, han sido puestos en entredicho en los últimos años, en base a la más reciente jurisprudencia del TC y a la postura que mantiene el Consejo de Estado en relación con el vigente artículo 25.2 de la LBRL.

Ello ha provocado una crisis en el sistema que podemos sistematizar en tres momentos concretos.

\section{$1^{\text {a }}$ CRISIS.- Desaparición del monopolio del legislador estatal para concretar el mínimo competencial garantizado} por la autonomía local constitucionalmente reconocida

Durante 20 años nadie había puesto en duda que el legislador estatal era el único competente para determinar el alcance competencial de la autonomía local y que dicha función era desarrollada por los artículos 2, 25.2 y 26 de la LBRL, en los términos que hemos analizado anteriormente.

Sin embargo, la Ley Orgánica 6/2006, de 19 de julio, de reforma del Estatuto de Autonomía de Cataluña (en adelante EAC), puso en entredicho este monopolio estatal al incluir, dentro del Capítulo VI "El gobierno local” del Título I, el artículo 84.2 que, tanto por su forma como por su contenido, era, a todas luces, la versión catalana del artículo 25.2 de la LBRL.

El Partido Popular recurrió ante el TC, no sólo el artículo 84.2 del EAC, sino varios artículos del Capitulo VI del Título I de dicha norma, al entender que contenían una regulación del régimen local impropia de un Estatuto ya que trataba de desplazar la legislación básica e impedir el ejercicio de la competencia estatal en la materia, persiguiendo una total "interiorización" del gobierno local que terminaría con el "carácter bifronte" que se desprende del art. 149.1.18 CE, reconocido jurisprudencialmente desde la STC 84/1982, de 23 de diciembre. Para los redactores del recurso, el capítulo partía de la idea de que la Ley de bases del régimen local puede ser parámetro de constitucionalidad de las leyes ordinarias, pero no de los Estatutos de Autonomía, que le están supraordenados. Aumentando la "densidad normativa" del Estatuto se evita que resulte aplicable en Cataluña el ejercicio de la competencia estatal de legislación básica, con la consecuencia de que las leyes catalanas sólo estarán vinculadas a lo dispuesto en el Estatuto. Con esta construcción se desbordarían los límites de la reserva estatutaria del art. 147.2 CE, en la que se incluye la organización de las "instituciones autónomas propias”, entre las que no se cuentan los entes locales, que son instituciones por sí y para sí, esto es, al servicio de sus propios intereses (art. 137 CE).

Lo anterior sería-continuaban los recurrentes-un ejemplo de la perturbación constitucional que entraña superar el ámbito propio de los Estatutos. Entre éstos y las leyes básicas no hay una relación de supra y subordinación, sino de competencia, y no cabe la sustitución de la función de la ley básica, aprobada exclusivamente por las Cortes Generales, por una ley, el Estatuto, en la que la voluntad de una parte de España es decisiva para su aprobación y reforma. Por ello el capítulo sería inconstitucional aun en los aspectos en que coincide con el contenido de la Ley de bases del régimen local. En definitiva, el Estatuto pretendería establecer su propio nivel de autonomía local, inmunizando al ordenamiento catalán frente a la garantía que la legislación básica ofrezca en cada momento en 
orden al aseguramiento de un nivel uniforme de autonomía local para todo el Estado, en línea con la doctrina sentada en la STC 32/1981, de 28 de julio [Antecedente 38 a) de la STC 31/2010].

Aparte de esta crítica general al capítulo VI del Título I del EAC, el Partido Popular impugnó expresamente la constitucionalidad del artículo 84.2 de dicha norma por entender que el mismo quiere ser el sustitutivo del art. 25.2 LBRL, del que copia su sistema, aunque no su enumeración, y debe completarse con el art. 84.3 y con el artículo 160.1 b), también impugnado, que confirmarían que será el legislador catalán el que establezca las competencias municipales en esas materias, sin concurso del legislador estatal. En conjunto, estos preceptos formarían un sistema encaminado a limitar al Estado la facultad de establecer normas básicas sobre las competencias locales. Lo que sería inconstitucional aun cuando se trate de materias propias de la Generalitat -pues el Estado puede imponer en todo caso cierta atribución a los entes locales como garantía mínima de su autonomía-y, desde luego, mucho más cuando, como sucede, por ejemplo, con las letras e), h) y l) del art. 84.2, se incluyen materias que son de la competencia del Estado [Antecedente 39 a) de la STC 31/2010].

Como vemos el Partido Popular plantea en su recurso que la regulación del régimen local contenida en el EAC supone la quiebra del sistema que venía operando desde la Constitución y la LBRL, al desconocer la competencia exclusiva del legislador estatal básico para concretar el ámbito competencial de la autonomía local, cuestión ésta que, como hemos dicho reiteradamente, la jurisprudencia del TC venía estableciendo de forma unánime. Recordemos que tanto la STC 32/1981como la 214/1989 nos decían que «Como titulares de un derecho de autonomía constitucional garantizada, las Comunidades locales no pueden ser dejadas en lo que toca a la definición de sus competencias y la configuración de sus órganos de gobierno a la interpretación que cada Comunidad Autónoma pueda hacer de ese derecho...».

Sin embargo el TC en su Sentencia 31/2010 consagró la constitucionalidad de todo el Capítulo VI del Título I del EAC y en particular del artículo 84.2 del mismo, en base a los siguientes argumentos (las negritas son mías):

En relación a la crítica general al Capítulo VI del Título I la STC nos dice (FJ 36):

“... En modo alguno cuestionan los recurrentes que las Comunidades Autónomas y, en concreto, la Comunidad Autónoma de Cataluña, al amparo de las previsiones del art. 149.1.18 CE puedan asumir, como efectivamente esta Comunidad Autónoma ha hecho (art. 160 EAC), competencias en materia de "régimen local", expresión ésta que hemos identificado con el "régimen jurídico de las Administraciones Locales" (STC 214/1989, de 21 de diciembre, FJ 1). Siendo ello así, como efectivamente lo es, en principio ninguna objeción puede formularse a que el Estatuto de Autonomía de la Comunidad Autónoma, en tanto que su norma institucional básica, contenga las líneas fundamentales o la regulación esencial, con el fin de vincular al legislador autonómico, del régimen local en el ámbito territorial la Comunidad Autónoma, debiendo respetar en todo caso las previsiones estatutarias, como es obvio, la competencia básica que al Estado corresponde en la materia en virtud de la reserva del art. 149.1.18 CE, por cuanto la expresión "bases del régimen jurídico de las Administraciones públicas" engloba a las Administraciones locales (ibidem). Así pues, sin una mayor argumentación y concreción impugnatoria por parte de los Diputados recurrentes, no puede estimarse que en su conjunto el capítulo VI transgreda la reserva estatutaria ex art. 147.2 CE, ni que impida el ejercicio de la competencia estatal en la materia.

En los mismos términos de generalidad y abstracción que los utilizados en el recurso, difícilmente puede afirmarse el fin del carácter bifronte del régimen local. Este carácter es el resultado "de la actividad concurrente del Estado ... y de las Comunidades Autónomas" (STC 84/1982, de 23 de diciembre, FJ 4), de modo que "[j] unto a una relación directa Estado- Corporaciones locales, existe también una relación, incluso más natural e intensa, entre éstas y las propias Comunidades Autónomas" (STC 331/1993, de 12 de noviembre, FJ 3). Y aquella concurrencia, como no podría ser de otra manera, ineludiblemente pervive en cuanto el ejercicio de las competencias autonómicas en materia de régimen local ha de ajustarse, necesariamente, a la competencia que sobre las bases de la misma corresponde al Estado ex art. 149.1.18 CE, por lo que la regulación estatutaria ha de entenderse, en principio, sin perjuicio de las relaciones que el Estado puede legítimamente establecer con todos los entes locales.

Por las razones expuestas ha de rechazarse la genérica crítica que los recurrentes dirigen contra el capítulo VI del título II del Estatuto." 
En relación al artículo 84.2 del EAC la STC nos dice (FJ 37):

“El artículo 84.2 EAC enumera una serie de materias sobre las que los gobiernos locales han de tener en todo caso competencias propias en los términos que determinen las leyes. Obviamente, como señala el Abogado del Estado, esta previsión estatutaria está dirigida al legislador autonómico y, por consiguiente, ha de entenderse que las materias sobre las que, según el precepto, los gobiernos locales han de tener en todo caso competencia son materias respecto de las cuales la Comunidad Autónoma ha asumido competencias, es decir, materias de competencia autonómica. Ello sentado, y sin perjuicio de lo que se dirá seguidamente en relación con las concretas materias cuestionadas por los recurrentes, ha de descartarse que el precepto desplace o impida el ejercicio de la competencia estatal en materia de bases del régimen local ex art. 149.1.18 CE, en virtud de la cual corresponde al legislador estatal fijar "unos principios o bases relativos a los aspectos institucionales (organizativos y funcionales) y a las competencias locales" de los entes locales constitucionalmente necesarios (STC 214/1989, de 21 de diciembre, FFJ 1 y 4). En otras palabras, el elenco competencial que el precepto estatutario dispone que tiene que corresponder a los gobiernos locales en modo alguno sustituye ni desplaza, sino que, en su caso, se superpone, a los principios o bases que dicte el Estado sobre las competencias locales en el ejercicio de la competencia constitucionalmente reservada por el art. 149.1.18 CE. La falta de una expresa mención en el precepto estatutario a la competencia estatal ex art. 149.1.18 CE ni vicia a dicho precepto de inconstitucionalidad, ni puede impedir de ninguna manera el ejercicio de esa competencia estatal (fundamentos jurídicos 59 y 64)."

De esta forma el TC reconoce el derecho de las Comunidades Autónomas a asumir competencias en materia de régimen local y, en consecuencia, a regular cuestiones relacionadas con el mismo, entre otras el ámbito competencial, si bien recuerda que dichas comunidades tienen la obligación de respetar la legislación básica del Estado y la función que la misma desempeña en nuestro ordenamiento jurídico local.

De esta forma, como dice la propia sentencia, el artículo 84.2 del EAC no sustituye ni desplaza al artículo 25.2 de la LBRL, sino que se superpone al mismo, resultando ambos de plena aplicación en dicha comunidad autónoma.

A mi juicio de la STC se desprende que el artículo 25.2 de la LBRL y el 84.2 del EAC tienen tres diferencias fundamentales:

1.- Por la función que desempeñan.- El artículo 25.2 de la LBRL tiene por objeto concretar el mínimo competencial que, en virtud de la autonomía local constitucionalmente garantizada, corresponde a todos los municipios españoles, mientras que el EAC, en su artículo 84.2, pretende, como norma institucional básica de dicha comunidad autónoma, garantizar a los municipios catalanes la atribución de competencias en determinadas materias de competencia autonómica, con independencia de que dichas materias estén o no incluidas en el listado del artículo 25.2 de la LBRL, posibilidad que encaja perfectamente en el esquema de atribución de competencias municipales que rige en nuestro país. Lo que no podría hacer, y no hace, el EAC es eximir al legislador sectorial catalán de atribuir competencias a sus municipios en alguna de las materias contenidas en el artículo 25.2 de la LBRL, ya que ello si supondría una suplantación de la competencia estatal para determinar el mínimo competencial garantizado por la autonomía local constitucionalmente reconocida. En otras palabras EAC no configura, ni podría hacerlo, el mínimo competencial atribuido a los entes locales catalanes en función de la autonomía local, ya que dicha autonomía, en cuanto atributo emanado directamente de la Constitución, ampara por igual a todos los municipios españoles, motivo por el cual su reflejo en el ámbito competencial únicamente puede ser precisado por el legislador estatal básico.

2.- Por el legislador afectado.- Ambos artículos constituyen un mandato al legislador sectorial para que, al regular determinadas materias, atribuya necesariamente competencias a los municipios. Sin embargo mientras que la LBRL vincularía tanto al legislador estatal como al legislador autonómico (a todos los legisladores autonómicos), el EAC únicamente estaría vinculando al legislador sectorial autonómico catalán, pero en ningún caso al legislador estatal. En este sentido sobre el legislador catalán recaería un doble mandato, por un lado estaría obligado a reconocer competencias a los municipios en todas las materias incluidas en el artículo 25.2 de la LBRL (en virtud del principio de autonomía local reconocido en la constitución y concretado por el legislador estatal en base al artículo 149.1.18 de la CE) y, por otro, debería atribuirles competencias en todas las materias del artículo 84.2 del EAC (en virtud del principio de jerarquía normativa, dado el carácter de norma institucional básica del Estatuto).

3.- Por su ámbito material.- El artículo 25.2 de la LBRL, en cuanto concreción de la autonomía local garantizada constitucionalmente, se refiere tanto a materias de competencia estatal como a materias de competencia autonómica. Por su parte el artículo 84.2 del EAC únicamente puede referirse a materias de competencia autonómica. 
En resumen ambos artículos se aplican de forma plena y simultánea en Cataluña, y así los municipios catalanes, como municipios españoles y en virtud de la autonomía local constitucionalmente garantizada, han de ostentar competencias en todas las materias recogidas en el artículo 25.2 de la LBRL, y como municipios pertenecientes a la Comunidad Autónoma Catalana han de ostentar competencias en aquellas materias de competencia autonómica determinadas en su Estatuto, pero éstas últimas no serán fruto de la autonomía local constitucionalmente garantizada, sino el resultado de la decisión del legislador estatutario catalán en uso de una doble competencia, por un lado de su competencia en materia de régimen local y por otro lado de su competencia en todas y cada una de las materias incluidas en el artículo 84.2 del EAC.

No considero acertado el entender que las competencias del artículo 84.2 del EAC sean el resultado de una autonomía local estatutariamente garantizada a los municipios catalanes, ya que dicha postura supondría el reconocimiento de una doble autonomía local, por un lado la reconocida constitucionalmente cuya concreción correspondería al legislador estatal básico, y por otro una autonomía local de ámbito autonómico cuya regulación correspondería al legislador de cada comunidad, ya que si la autonomía local deriva del carácter esencial de los entes locales constitucionales (municipios y provincias) en la configuración del Estado, el reconocimiento de dicha autonomía deberá corresponder a la constitución y amparar por igual a todos los municipios españoles que, en cualquier parte del territorio nacional, ostentan de igual forma dicho carácter esencial.

\section{$2^{\text {a }}$ CRISIS.- El artículo 25.2 no forma parte del bloque de constitucionalidad}

Como hemos dicho el Tribunal Constitucional (Sentencia 159/2001) venía considerando que aquella parte de la LBRL que sea concreción de principios constitucionales podría integrarse sin dificultad dentro del llamado bloque de constitucionalidad (art. 28.1 de la LOTC), por lo que, dado que el artículo 25.2 de la LBRL constituía la concreción del principio constitucional de autonomía local en su vertiente competencial, no había problema en admitir que dicho artículo formaba parte del bloque de constitucionalidad.

Sin embargo la STC 240/2006 (primera dictada por el TC para resolver un conflicto en defensa de la autonomía local) parece apartarse de esta postura, y así nos dice:

“...de la jurisprudencia examinada no se concluye que la Ley reguladora de las bases del régimen local constituya siempre canon de validez de la ley, estatal o autonómica, a la hora de enjuiciar normas que desarrollen aspectos concretos de la autonomía local. De la ley estatal no lo constituye porque la Ley de las bases del régimen local, más allá de la referida naturaleza singular, y de su carácter básico ex art. 149.1.18 CE, no ocupa en nuestro Ordenamiento una posición distinta a las demás leyes ordinarias del Estado, que pueden por tanto establecer disposiciones contrarias a la Ley de las bases del régimen local, las cuales deberán ser consideradas modificaciones legislativas pero no leyes inconstitucionales. De la ley autonómica sólo podría ser canon de validez la Ley de las bases del régimen local en aquellos aspectos enraizables directamente en los arts. 137, 140 y 141 CE."

En efecto, tal como declaró la STC 159/2001, de 5 de julio, "Sólo aquellos extremos de la LBRL que puedan ser cabalmente enraizados de forma directa en los arts. 137, 140 y 141 CE, de cuyo contenido no representen más que exteriorizaciones o manifestaciones, forman parte del contenido de la autonomía local constitucionalmente garantizada, mientras que los que se refieran a aspectos secundarios o no expresivos de ese núcleo esencial en el que consiste la garantía institucional, que son mayoría en el seno de la LBRL y que se incardinan, desde el punto de vista competencial, en el art. 149.1.18 CE, tienen una distinta naturaleza desde el punto de vista constitucional y ordinamental" (FJ 4).

“...la legislación básica sobre régimen local no se integra en el "bloque de la constitucionalidad" ni constituye canon de validez respecto de otras leyes estatales. Tal como sostiene el Abogado del Estado no puede pretenderse de este Tribunal que enjuicie una norma estatal utilizando como parámetro otra norma estatal (configuradora de la autonomía local constitucionalmente garantizada) pues, lógicamente, si no se ha vulnerado la Constitución debe interpretarse como una nueva opción del legislador."

6 Sobre esta Sentencia ver Javier García Roca, “La primera sentencia constitucional sobre conflicto en defensa de la autonomía local (STC 240/2006): Una ocasión pérdida”, Tomás Font i Llovet, “Autonomía Local y Estatutos: Crónica de un compromiso”, Luís Pomed Sánchez “Jurisprudencia constitucional sobre administración local. Primera sentencia dictada en un conflicto en defensa de la autonomía local” o Cayetano Núñez Rivero y Santiago García Aranda “La autonomía de los entes locales". 
Por lo tanto a partir de esta Sentencia parece que el artículo 25.2 de la LBRL deja de tener carácter vinculante respecto del legislador estatal, el cual, al regular cualquiera de las materias contenidas en dicho artículo podrá optar por no atribuir ninguna competencia a los municipios, sin que dicha determinación, por si misma, esté afectada de inconstitucionalidad, dado que al ser la LBRL una mera ley ordinaria, en ningún caso podrá ser considerada canon de validez del resto de las leyes ordinarias del Estado, las cuales, en caso de apartarse del criterio de la LBRL, deberán considerarse como una mueva opción legislativa, cuyo acomodo a la Constitución deberá dilucidarse por el TC, en base a lo que resulte del texto constitucional y de su propia jurisprudencia, pero no en base al contenido de la LBRL.

La situación no cambia en lo referente al legislador autonómico, ya que, conforme a la Sentencia, la LBRL constituye canon de validez de la legislación autonómica (y por lo tanto vincula al legislador sectorial autonómico) “en aquellos aspectos enraizables directamente en los arts. 137, 140 y 141 CE”, por lo que, si el artículo 25.2 de la LBRL constituye la concreción de la autonomía local y ésta aparece reconocida en los artículo 137 y 140 de la CE, podemos afirmar que el artículo 25.2 de la LBRL está enraizado directamente en los artículos 137 y 140 de la CE, constituyendo canon de validez de la legislación autonómica.

A pesar de que el TC argumenta que la doctrina consagrada en la Sentencia citada no supone una modificación de la jurisprudencia constitucional sino que, al contrario, se asienta en ella, considero que, al menos, afecta a la posición que la LBRL ha venido ostentando en el ordenamiento jurídico español, disminuyendo considerablemente su importancia.

La doctrina resultante de la STC 240/2006, supone que, en relación al legislador estatal, el artículo 25.2 de la LBRL perdería la posición que ha venido ocupando en nuestro ordenamiento jurídico, ya que dejaría de ser la concreción del mínimo competencial garantizado a los municipios en virtud del principio de autonomía local, para convertirse en un listado de materias meramente orientativo sin ninguna fuerza vinculante.

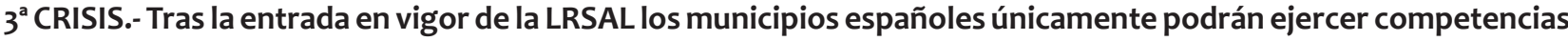
en las materias determinadas en el artículo 25.2 de la LBRL

Dicho de otra forma, el listado de materias contenido en el 25.2 de la LBRL deja de ser "de mínimos" para convertirse en un listado "de máximos" (o por mejor decir “de mínimos” y “de máximos” al mismo tiempo) en lo que a las competencias municipales se refiere.

Dicha apreciación no es unánime, siendo la polémica en torno a la misma la principal discusión a que ha dado lugar la LRSAL, ya que de confirmarse dicha interpretación por el TC supondría una auténtica revolución en el régimen local.

Las principales posturas que se han mantenido al respecto son las siguientes:

1.- Posturas que consideran que la LRSAL supone una modificación del sentido del artículo 25.2 de la LBRL, defendida fundamentalmente por el Consejo de Estado?.

El Consejo de Estado nos dice en su dictamen 338/2014, de 22 de mayo, nos dice que:

“...la LRSAL ha modificado el artículo 25.2 de la LBRL con el objeto de que los municipios sólo puedan ejercer competencias propias sobre las materias mencionadas en dicho precepto, de forma que el ejercicio de competencias municipales sobre cualesquiera otras materias deberá atribuirse necesariamente por delegación del Estado o de las Comunidades Autónomas de conformidad con el artículo 27 de la LBRL, o sujetarse a los requisitos específicos de las competencias distintas de las propias o de las atribuidas por delegación, establecidos en el artículos 7.4 de la LBRL."

2.- Posturas que entienden que la LRSAL no modifica el sentido del artículo 25.2 de la LBRL cuyo listado mantiene su carácter "de mínimos", defendida por el Ministerio de Hacienda y Administraciones Públicas (departamento responsable de la LRSAL).

En este sentido, en respuesta a diversas consultas,la Dirección General de Coordinación de Competencias con las CC. AA. y las Entidades Locales, de la Secretaria de Estado de Administraciones Públicas ha mantenido la postura tradicional en relación con el artículo 25.2 de la LBRL.

Así podemos citar los siguientes informes de la mencionada Dirección General:

7 Desde el punto de vista doctrinal defienden esta postura, entre otros Pilar Navarro Rodríguez y Manuel Zafra Víctor (2014) “La conclusión, por tanto, aparece inequívoca a nuestro parecer: fuera del listado del artículo 25.2 las competencias será delegadas o impropias; el legislador autonómico no podrá atribuir competencias propias en otras materias de las allí enumeradas." 
A) Asunto: Re: Fwd: e-637.- RV: COMPETENCIAS ENTIDADES LOCALES, en respuesta a una consulta formulada por la Interventora del Ayuntamiento de Posadas (Córdoba).

La Ley 27/2013, de 27 de diciembre, de Racionalización y Sostenibilidad de la Administración Local (en adelante, LRSAL), ha introducido cambios en el sistema de atribución de competencias a los municipios, modificando diversos preceptos de la Ley $7 / 1985$, de 2 de abril, reguladora de las Bases del Régimen Local (en adelante, LRBRL), con el objetivo fundamentalmente de evitar duplicidades administrativas y clarificar las competencias, asegurando al mismo tiempo su sostenibilidad financiera.

De manera que cualquier cuestión relativa a las competencias municipales, requiere hacer previamente un breve análisis del nuevo sistema competencial para poder pasar posteriormente a analizar la legislación sectorial específica. Las características de este nuevo modelo se pueden resumir como se indica a continuación.

En primer lugar, el art. 25.1 de la LRBRL (según la nueva redacción dada por la LRSAL) recoge una cláusula de carácter general de alcance limitado, puesto que reconduce la posibilidad de promover actividades y prestar servicios públicos que contribuyan a satisfacer las necesidades de la comunidad vecinal a los términos previstos en el propio artículo 25.

En segundo lugar, en el apartado 2 de dicho artículo se enumeran una serie de materias en las que el legislador sectorial, estatal y autonómico, ha de determinar en todo caso las competencias propias municipales. En ese nuevo listado ya no figuran algunos ámbitos materiales que aparecían en la redacción originaria de 1985 o aparecen con una redacción más concretizada.

En particular, entre las materias allí enumeradas no figura actualmente la defensa de usuarios y consumidores, a la que se hace referencia en el escrito de consulta. Antes dicha materia estaba contemplada en el artículo $25.2 \mathrm{~g}$ ).

No obstante lo anterior, la LRSAL no prohíbe el ejercicio por los municipios de competencias en esos otros ámbitos materiales no recogidos en el art. 25.2. Éstos podrán ejercerlas en los siguientes casos:

$\left.1^{\circ}\right)$.- Teniendo en cuenta el modelo de distribución constitucional de competencias previsto en los arts. 148 y 149 CE, nada impide que las Comunidades Autónomas, en las materias en las que hayan asumido competencias legislativas en sus respectivos Estatutos de Autonomía, identifiquen las concretas competencias que corresponden al municipio en su legislación sectorial atribuyéndolas como propias (apartados 1 y 2 del art. 7 de la LRBRL).

De manera que habrá que analizar, en primer lugar, si el legislador sectorial autonómico, cuando sea competente por razón de la materia, ha atribuido como propia, la competencia de que se trate a los municipios.

Y en iguales términos sucede en el caso de las materias de la legislación estatal. En ambos casos, hay que señalar que desde la entrada en vigor de la Ley, la determinación de las competencias propias habrá de cumplir las garantías previstas en los apartados 3, 4 y 5 del art. 25.".

B) Asunto: Re: Fwd: e-545.- RV: CONSULTA SOBRE CUESTIONES DE LA LEY 27.2013, en respuesta a consulta formulada por la Diputación Provincial de Almería.

“A).- El régimen de las competencias propias en el art. 25 LRBRL

En primer lugar Ley 7/1985, de Bases de Régimen Local en su art. 25.1, (según la nueva redacción dada por la LRSAL) recoge una cláusula de carácter general de alcance limitado, puesto que reconduce 
la posibilidad de promover actividades y prestar servicios públicos que contribuyan a satisfacer las necesidades de la comunidad vecinal a los términos previstos en el propio artículo 25.

En segundo lugar, en el apartado 2 de dicho artículo se enumeran una serie de materias en las que el legislador sectorial, estatal ${ }^{8}$ y autonómico, en todo caso ha de determinar competencias propias municipales. En ese nuevo listado ya no figuran algunos ámbitos materiales que aparecían en la redacción originaria de 1985 o aparecen con una redacción más concretizada. No obstante lo anterior, la LRSAL no prohíbe el ejercicio por los municipios de competencias en esos otros ámbitos materiales no recogidos en el art. 25.2.

En este sentido, teniendo en cuenta el modelo de distribución constitucional de competencias previsto en los arts. 148 y 149 CE, nada impide que las Comunidades Autónomas, en las materias en las que hayan asumido competencias legislativas en sus respectivos Estatutos de Autonomía, identifiquen las concretas competencias que corresponden al municipio en su legislación sectorial atribuyéndolas como propias (apartados 1 y 2 del art. 7 de la LRBRL)."

A la postura de la D.G. pueden añadirse los siguientes argumentos adicionales:

\section{1.- Por el significado del artículo 25.2 de la LBRL en el ordenamiento jurídico local español.}

Como hemos visto el significado del artículo 25.2 de la LBRL en nuestro ordenamiento jurídico es concretar, junto con el artículo 2 de la misma ley, el mínimo competencial que corresponde a los municipios en virtud de la autonomía que la CE les garantiza. Si a eso añadimos que la LRSAL no supone la modificación de la estructura o de los principios básicos de la LBRL, hemos de concluir que la LRSAL no altera la posición del artículo 25.2 de la LBRL, por lo que la enumeración que contiene dicho artículo siguen constituyendo el mínimo de materias en las que los municipios deben ostentar competencias.

\section{2.- Desde el punto de vista de la literalidad del precepto.}

El primer párrafo del artículo 25.2 de la LBRL nos decía antes de la LRSAL:

“2. El Municipio ejercerá, en todo caso, competencias en los términos de la legislación del Estado y de las Comunidades Autónomas en las siguientes materias:...".

La expresión "en todo caso" equivale a "siempre” o "necesariamente" (este último término se emplea por el TC en el fundamento jurídico $3^{\circ}$ de la Sentencia 214/1989), y consagra el carácter de mínimos de dicho artículo. Por otro lado la referencia a la legislación del Estado y de las Comunidades Autónomas hacía de dicho artículo un mandato para ambos legisladores al regular las materias contenidas en el mismo. Lo único que dicho artículo no determinaba era el alcance de las competencias locales en las materias que incluía, sin que ello supusiera que dicho extremo quedara enteramente en manos del legislador sectorial, ya que el mismo debería respetar en dicho punto los principios del artículo 2.1 de la misma LBRL.

Pues bien el primer párrafo del artículo 25.2 de la LBRL en la redacción dada por la LRSAL es el siguiente: “El municipio ejercerá en todo caso como competencias propias, en los términos de la legislación del estado y de las Comunidades Autónomas, en las siguientes materias:..."

Como vemos la LRSAL no modifica el párrafo introductorio del artículo 25.2, salvo en el sentido de exigir que las competencias que el legislador sectorial atribuya a los municipios en las materias incluidas en el mismo lo sean con carácter de propias (cuyo significado ya hemos visto anteriormente), permaneciendo inalterado el resto del párrafo, por lo tanto si la literalidad del párrafo no se modifica, no debe entenderse modificado el sentido del mismo, y, en concreto, si se mantiene la expresión "en todo caso", que es la que confería carácter "de mínimo" al listado de materias del artículo analizado, no se entiende la tesis que postula que dicho listado pasa ahora a tener carácter de "numerus clausus".

3.- La más reciente jurisprudencia del TC que permite a las Comunidades Autónomas y al Estado conceder competencias a los municipios en materias no incluidas en el artículo 25.2 de la LBRL.

\subsection{En relación a las Comunidades Autónomas: STC 31/2010 relativa al EAC.}

Dicha Sentencia reconoce expresamente que los Estatutos de Autonomía pueden garantizar a los

8 La Dirección General sigue manteniendo la vinculación del legislador sectorial estatal al listado del artículo 25.2 de la LBRL, desconociendo la doctrina constitucional iniciada con la STC 240/2006.

REALA, n 3, enero-junio 2015, ISSN: 1989-8975 - DOI: http://dx.doi.org/10.24965/reala.v0i3.10244 
municipios la atribución de competencias en materias de competencia autonómica, con independencia de que dichas materias estén o no incluidas en el artículo 25.2 de la LBRL, lo que resultaría incompatible con un artículo 25.2 de máximos.

\section{2.- En relación al Estado: STC 240/2006}

Conforme a dicha Sentencia el legislador sectorial estatal no se encuentra vinculado por la LBRL, y cualquier ley ordinaria que se aparte de los criterios contenidos en la misma deberá ser entendida como una nueva opción legislativa. Por lo tanto el legislador estatal puede, en cualquier caso, atribuir a los municipios competencias en cualquier materia, con independencia de lo que diga el artículo 25.2 que, conforme a dicha doctrina, no sólo no será un artículo de máximos, sino que ni siquiera será un artículo de mínimos, ya que no vincula al legislador estatal.

\section{4.- Comparación con el artículo 36 de la LBRL}

Como hemos visto anteriormente el TC, en el fundamento jurídico $3^{\circ}$ de la Sentencia 214/1989, nos dice que el artículo 25.2 de la LBRL delimita las materias en las que necesariamente deben atribuirse competencias a los municipios y que dicha función es desempeñada respecto de las provincias por el artículos 36 de la LBRL.

Por lo tanto si el artículo 25.2 y el artículo 36 de la LBRL tienen la misma función (uno respecto de los municipios y otro respecto de las provincias) resulta perfectamente posible integrar a efectos interpretativos el uno con el otro, de forma que si el artículo 36 de la LBRL no plantea ninguna duda en relación al carácter de mínimos del listado de materias que contiene, no existe ningún motivo para defender que el artículo 25.2 tenga, por el contrario, carácter de máximo.

5.- Por último existe un importante argumento de carácter práctico, como es la existencia de numerosa normativa sectorial que concede a los municipios competencias en materias no incluidas en el artículo 25.2 de la LBRL.

En este sentido podemos citar sin ánimo exhaustivo:

1.- Ley Orgánica 5/1985, de 19 de junio, del Régimen Electoral General, cuyo artículo 26.1 nos dice:

"La formación de las Mesas compete a los Ayuntamientos, bajo la supervisión de las Juntas Electorales de Zona."

2.- El artículo 49 del Código Civil nos dice:

“Cualquier español podrá contraer matrimonio dentro o fuera de España:

$1^{\circ}$ Ante el Juez, Alcalde o funcionario señalado por este Código.

$2^{\circ}$ En la forma religiosa legalmente prevista"

3.- El artículo 101 de la Ley Orgánica 6/1985, de 1 de julio, de I Poder Judicial, nos dice:

“1. Los Jueces de Paz y sus sustitutos serán nombrados para un período de cuatro años por la Sala de Gobierno del Tribunal Superior de Justicia correspondiente. El nombramiento recaerá en las personas elegidas por el respectivo Ayuntamiento.

2. Los Jueces de Paz y sus sustitutos serán elegidos por el Pleno del Ayuntamiento, con el voto favorable de la mayoría absoluta de sus miembros, entre las personas que, reuniendo las condiciones legales, así lo soliciten. Si no hubiere solicitante, el Pleno elegirá libremente."

Es claro que ni antes ni ahora el artículo 25.2 ha reconocido competencias a los municipios en materia electoral, en materia de estado civil o en materia de justicia, por lo cual, si este fuera de máximos, los Ayuntamientos desde el 31 de diciembre de 2015 no serían competentes para formar las mesas electorales (no sé cómo se hubieran podido celebrar procesos electorales desde aquella fecha), para celebrar matrimonios civiles o para elegir a los candidatos a Juez de Paz.

Son sólo tres ejemplos, quizás los más llamativos, pero si repasamos la legislación estatal o autonómica nos encontraremos con multitud de casos en los cuales la normativa sectorial atribuye a los municipios competencias 
en materias no incluidas en el artículo 25.2 de la LBRL (parejas de hecho, protección de los animales, custodia de objetos desaparecidos, extranjería, etc.).

Por lo tanto en mi opinión esta "tercera crisis del sistema" no lo es tal, ya que el artículo 25.2 de la LBRL continúa fijando el mínimo competencial que corresponde a los municipios.

Ahora bien, el sólo hecho de que se haya provocado esta discusión en torno al carácter del artículo 25.2 de la LBRL nos habla de la escasa calidad técnica de un precepto que, lejos de venir a mejorar las cosas, parece haber sido redactado con la intención de crear confusión en la materia que regula.

Por motivos de espacio no es posible realizar un estudio crítico pormenorizado de la vigente redacción del artículo 25.2 de la LBRL, pero si me gustaría decir que, desde mi punto de vista, contiene numerosas deficiencias, entre las que podrían destacarse las dos siguientes:

1.- La relación de materias que contiene es manifiestamente mejorable, al no incluir determinadas materias que en la conciencia popular están unidas a la actividad municipal. En este sentido considero desafortunada la supresión de la protección de los consumidores y usuarios y, sobre todo, que no se haya aprovechado la oportunidad para incluir otras materias tradicionalmente vinculadas a la actuación municipal como "la celebración del matrimonio".

2.- Confunde materias con competencias, lo que supone que, en algunos supuestos, parece actuar como máximo. En este sentido las letras e) y $n$ ) descienden a tal grado de detalle que más que enumerar materias atribuyen competencias concretas, haciendo irrelevante el posterior desarrollo sectorial (difícilmente el legislador sectorial podrá concretar más de lo que especifican dichos apartados). Hasta tal punto llega dicha confusión que el inciso final del apartado n) copia literalmente las competencias municipales establecidas por la legislación sectorial

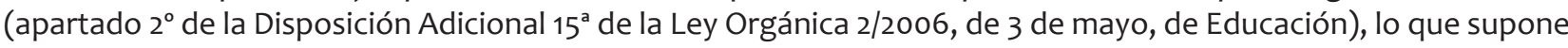
un profundo desconocimiento del sistema de atribución de competencias municipales.

\section{6.- DISPOSICIONES TRANSITORIAS PRIMERA, SEGUNDA Y TERCERA DE LA LRSAL. DELIMITACION NEGATIVA DE LA AUTONOMIA LOCAL}

Las disposiciones transitorias $1^{\mathrm{a}}, 2^{\mathrm{a}}$ y $3^{\mathrm{a}}$ de la LRSAL vienen a establecer que las Comunidades Autónomas asumirán, en los plazos establecidos por las mismas, la titularidad de las competencias que se preveían como propias del Municipio relativas a la participación en la gestión de la atención primaria de la salud (D.T. $\left.1^{\mathrm{a}}\right)$ y en materia de servicios sociales y de promoción y reinserción social (D.T. $2^{\mathrm{a}}$ ), debiendo igualmente las Comunidades Autónomas prestar los servicios relativos a la inspección y control sanitario de mataderos, de industrias alimentarias y bebidas que hasta ese momento vinieran prestando los municipios (D.T. $3^{\mathrm{a}}$ ).

Las Disposiciones Transitorias $1^{\mathrm{a}}$ y $2^{\mathrm{a}}$ configuran dicha asunción como obligatoria para las Comunidades Autónomas, de donde se infiere que éstas no podrán atribuir a los municipios competencias propias en las materias reguladas por las referidas disposiciones transitorias, ya que no tendría sentido que la Comunidad Autónoma tuviera que asumir la titularidad de las competencias que los municipios venían ostentando como propias para, a continuación, volver a atribuirlas a las entidades locales como competencias propias.

La D.T. $3^{\text {a }}$ no habla de asunción de titularidad, sino que se limita a establecer que las Comunidades Autónomas prestarán los servicios que hasta el momento venían prestando los municipios, sin embargo parece claro que la obligación de prestar el servicio debe conllevar la titularidad de la competencia.

Por lo tanto, y refiriéndonos exclusivamente a lo que interesa al presente artículo, las disposiciones transitorias $\mathbf{1}^{\mathrm{a}}, \mathbf{2}^{\mathrm{a}}$ y $\mathbf{3}^{\mathrm{a}}$ de la LRSAL impiden a las Comunidades Autónomas atribuir competencias propias a los municipios en las materias reguladas por las mismas, aun cuando las Comunidades sean competentes por razón de la materia, en resumen introducen lo que hemos denominado "delimitación negativa de la autonomía local”.

Esta cuestión, de enorme importancia, obliga a plantearnos si el legislador estatal básico está habilitado para llevar a cabo dicha delimitación.

El debate debe plantearse en el sentido de si la habilitación que tiene el legislador básico para concretar la garantía institucional de la autonomía local se reduce, como hemos visto hasta ahora, a la formulación de unas bases en relación con el mínimo competencial de los entes locales o si, por el contrario, el legislador estatal está igualmente habilitado para fijar idénticos principios o bases en relación al máximo de competencias que puedan asumir dichos entes, lo que, en caso de admitirse, supondría que el legislador sectorial tendría dos límites a la hora de atribuir competencias a municipios y provincias, por un lado vendría obligado a atribuir competencias a dichos entes en todo lo relativo al mínimo competencial (vinculación positiva) y por otro tendría prohibido atribuir 
competencias a los mismos en todo aquello que excediera del máximo fijado por el legislador estatal (vinculación negativa).

Si la garantía institucional de la autonomía local (en su vertiente competencial) se configura exclusivamente como la existencia de un mínimo que en todo caso debe corresponder a los municipios y si el legislador básico sólo está habilitado para establecer principios o bases en materia competencial como forma de garantizar la autonomía local, el legislador estatal podrá, en base a dicha habilitación, garantizar dicho mínimo, pero no podrá limitar las competencias que, en virtud de la legislación sectorial, pueden asumir los entes locales, dado que la autonomía local no ampara ninguna limitación en este sentido.

Sin embargo la cuestión no resulta tan clara si hacemos hincapié en la consideración del TC de que la garantía institucional comprende la preservación de la institución en términos recognoscibles para la imagen que de la misma tiene la conciencia social en cada tiempo y lugar, porque, como dijimos anteriormente, dicha consideración obligaría al legislador básico (como garante de la autonomía local) a determinar, en cada momento histórico, que entiende la sociedad por municipio, es decir que ámbitos de actuación administrativa son identificados por los ciudadanos como campos de actuación propios de sus Ayuntamientos y, por el contrario, que aspectos de la actividad pública son considerados por la conciencia social como impropios de la actuación municipal. En este sentido tan irreconocible para la conciencia social sería un municipio sin competencias urbanísticas como un municipio que expide títulos universitarios.

Esta delimitación negativa de la garantía institucional está latente en el dictamen del Consejo de Estado $\mathrm{n}^{\circ}$ 2628/2004, relativo al Expediente de Anteproyecto de Ley por la que se modifica el Código Civil en materia de derecho a contraer matrimonio (ley de matrimonio homosexual), donde el Alto Organismo Consultivo plantea la posibilidad de que la apertura de la institución matrimonial a parejas del mismo sexo determine una alteración de la institución matrimonial, que suponga una ruptura de la concepción social vigente en España en nuestros días. Independientemente del resultado final de aquella concreta cuestión (resuelto en favor de la constitucionalidad de la norma por la STC 198/2012, de 6 de noviembre), lo cierto es que dicho argumento nos puede servir como punto de partida para que, en la materia que nos ocupa, nos planteemos si la atribución de determinadas competencias a los municipios puede alterar la naturaleza de la institución, rompiendo con la concepción social vigente en España.

La concepción que la sociedad tiene en cada momento de una institución, es la síntesis de lo que es (en este sentido un municipio para ser reconocible por la conciencia social debe tener competencias en materia de urbanismo, tráfico urbano, cementerio, abastecimiento de agua, limpieza viaria, etc.) y de lo que no es (un municipio no concede títulos educativos ni mantiene relaciones internacionales).

En base a ello considero que una delimitación negativa de la autonomía local (entendiendo por tal la determinación de una serie materias en las que no podrán ostentar competencias los entes locales, ya que la asunción de las mismas rompería con la concepción social de la institución vigente en España en nuestros días), es perfectamente posible y resulta amparada por la consideración de la garantía institucional de la autonomía local como recognoscibilidad social de la institución, consagrada por nuestro TC.

Ahora bien, dicha delimitación negativa de la autonomía local debe obedecer a criterios ${ }^{9}$ perfectamente determinados, entre los que podrían incluirse los siguientes:

Por la naturaleza de las materias excluidas: No cabría atribuir competencias a las entidades locales en materias totalmente ajenas al interés local. Ahora bien, si entendemos por interés local todo aquello que afecte a la comunidad vecinal (conjunto de vecinos de una localidad) es difícil imaginar materias totalmente ajenas a dicho interés (¿relaciones exteriores? ¿defensa nacional?).

Por motivos organizativos: Existen determinados servicios que, por su coste y grado de complejidad, no pueden ser adecuadamente gestionados por las entidades locales, debiendo ser asumidos por otras Administraciones con mayor capacidad de gestión. Esta limitación se deriva del principio de subsidiariedad, conforme al cual las competencias deben ser asumidas por las administraciones más próximas al ciudadano en función de su capacidad de gestión.

En este sentido deben entenderse las Disposiciones Transitorias $1^{\mathrm{a}}$ y $2^{\mathrm{a}}$ de la LRSAL, dado que las materias que regulan (sanidad y servicios sociales) deben ser gestionadas por Administraciones de base territorial más amplía que las locales, dado que una eficiente prestación de dichos servicios, por lógicas exigencias de economía de escala, requieren una programación supramunicipal. Sería absurdo e inviable planificar la sanidad o los servicios

9 Sobre este punto Ricard Gracia Retortillo en su artículo “La autonomía local en Alemania” (2000) nos dice que: “De acuerdo con su concepción jurisprudencial habitual, [...] el legislador únicamente puede retirar competencias a los municipios por motivos de interés general, [...]. Motivos como la simplificación administrativa o la concentración de competencias no se admiten como justificación para atribuir una competencia local a otra entidad pública distinta al municipio."

REALA, n 3, enero-junio 2015, ISSN: 1989-8975 - DOI: http://dx.doi.org/10.24965/reala.v0i3.10244 
sociales municipio por municipio.

\section{7.- BREVE VALORACION DE LA LRSAL Y PROPUESTAS DE REFORMA}

Probablemente la LRSAL sea una ley necesaria, pero también es errónea en su planteamiento y deficiente en su articulación.

Es una ley necesaria, dado que en los últimos años se había producido, por la vía de los hechos, una ampliación desmedida de las competencias locales, lo que había degenerado en la ejecución de obras y prestación de servicios que no respondían a las necesidades reales de la población, generalizándose entre amplios sectores de la sociedad la idea de que en los ayuntamientos se "tiraba" el dinero público.

Esta asunción indiscriminada de competencias por parte de los municipios podía encontrar un cierto apoyo jurídico en el derogado artículo 28 de la LBRL y en el concepto amplio de autonomía local que, por ejemplo, defiende el Tribunal Supremo en su Sentencia de 30 de Enero de 2008, (recurso 1346/2004) cuando nos dice que,

"la autonomía local no está constituida por un catálogo de competencias objetivamente determinado o que pueda determinarse sobre la base de unas características invariables, sino más bien mediante la facultad de asumir, sin título competencial especial, todas aquellas tareas que afecten a la comunidad vecinal que integra el municipio y que no hayan puesto en funcionamiento otras administraciones públicas".

En base a ello los municipios gozarían de una especie de "competencia universal"10 que les legitimaría a prestar cuantos servicios tuvieran por conveniente, siempre que afectaran a la comunidad vecinal y no incurrieran en duplicidad. Sin embargo este posible amparo competencial no justifica la realización de obras o la puesta en funcionamiento de servicios totalmente superfluos e innecesarios.

Pero si la LRSAL era necesaria en el sentido de introducir la racionalidad en el gasto público local, considero que la forma que tiene de afrontar dicho problema es errónea o, al menos, poco adecuada.

La LRSAL, y ese es quizás su principal defecto, no pretende introducir la racionalidad y la eficiencia en el gasto público local, sino que, sencillamente, trata de reducirlo, y lo hace consagrando la máxima "una administración una competencia" y exigiendo el cumplimiento del objetivo de estabilidad presupuestaria.

Para empezar estas principios no constituyen ninguna novedad, ya que ambos estaban consagrados en el ordenamiento jurídico español, mucho antes de la LRSAL.

Por un lado, en cuanto a la interdicción de la duplicidad en la prestación de servicios públicos, acabamos de ver como el TS vedaba a los municipios la posibilidad de asumir tareas que hubieran puesto en funcionamiento otras administraciones públicas, y si miramos más atrás el artículo 31.2 del Reglamento de Servicios nos decía (y nos sigue diciendo) :

"Se evitará la duplicidad de servicios prestados por otros Organismos públicos con competencia especialmente instituida para el desarrollo de los mismos."

En cuanto a la estabilidad presupuestaria, es cierto que la Ley Orgánica 2/2012, de 27 de abril, de Estabilidad Presupuestaria y Sostenibilidad Financiera establece nuevos objetivos en la materia (regla de gasto), pero debemos recordar que el Texto Refundido de la Ley Reguladora de las Haciendas Locales, aprobado por Real Decreto Legislativo 2/2004, de 5 de marzo (en adelante LRHL), establece en su artículo 193 medidas muy concretas para el supuesto de liquidación del presupuesto con remanente de tesorería negativo (reducción de gastos del nuevo presupuesto, concierto de una operación de crédito por su importe siempre que se cumplan las condiciones del artículo 177.5 de dicha ley o aprobación del presupuesto del ejercicio siguiente con un superávit inicial de cuantía no inferior al repetido déficit).

Pero, y volviendo estrictamente al tema competencial, no es sólo que la LRSAL aporte pocas novedades e introduzca un grado considerable de confusión, sino que además yerra el enfoque, porque, si de lo que se trata es de conseguir una Administración local más eficiente en la gestión del dinero público, el problema no es tanto que el gasto responda a las competencias municipales, como que responda a las necesidades de la comunidad vecinal.

10 Esta concepción se desarrolla en Alemania y así Ricard Gracia Retortillo (2000) nos dice: “En virtud del principio de universalidad, el municipio tiene garantizada constitucionalmente la capacidad para asumir — sin necesidad de título competencial específico- todas las tareas que se definan como asuntos de la comunidad local y que no estén atribuidas previamente a otros sujetos administrativos." 
Pensemos en una entidad local que construye un aeropuerto en su ámbito territorial, que invierte miles de millones en dicha obra y que dicho aeropuerto no llega a ponerse en funcionamiento al no responder dicha instalación a una necesidad real de la sociedad y de la economía de la zona. En este caso ¿cuál es el problema? ¿que la entidad local promotora del aeropuerto no tenga competencias en materia de transporte aéreo o infraestructuras aeroportuarias o que la entidad local haya malgastado el dinero público en una obra sin ninguna utilidad?

Si el aeropuerto de nuestra ejemplo tuviera una utilización importante, generará beneficios (o al menos no arrojara pérdidas) a medio-largo plazo y contribuyera de forma notable al desarrollo económico y social de su entorno, su construcción hubiera sido una gestión eficiente del dinero público, con independencia de que la entidad local promotora tuviera o no tuviera competencias para afrontar dicha obra. Por el contrario si el aeropuerto de nuestro ejemplo no llega a ponerse en funcionamiento, su construcción constituiría una desastrosa gestión del dinero público, aun cuando la entidad local tuviera todas las competencias del mundo para su ejecución.

Que no se entienda el párrafo anterior como el beneplácito para que las Administraciones públicas afronten cualesquiera actuaciones sin estar legalmente habilitadas para ello, cuestión con la que manifiesto mi total desacuerdo, sino con la idea de que la eficiencia en la gestión del gasto público no se consigue recortando competencias, sino estableciendo un sistema que por un lado garantice que las obras que se ejecutan o los servicios que se prestan responden a las necesidades reales de la población y que por otro establezca un sistema de responsabilidad rápido y eficaz para el caso de que el dinero público se derroche en obras o servicios carentes de utilidad.

Dicha postura aparece recogida de manera magistral en el artículo 31.1 del Reglamento de Servicios de las Corporaciones Locales que nos dice: "Con el fin de atender a las necesidades de sus administrados, las Corporaciones Locales prestarán los servicios adecuados para satisfacerlas”, expresión que condensa los principios de racionalidad y eficiencia en el gasto público con una precisión y claridad digna del mayor de los elogios.

Pero el Reglamento de Servicios no sólo se queda en el ámbito de las declaraciones generales, sino que regula en sus artículos 56 y siguientes el famoso expediente de municipalización que, con las lógicas y necesarias actualizaciones, sería un instrumento idóneo para determinar si las iniciativas locales responden a necesidades reales de la población, son adecuadas para satisfacerlas y resultan financieramente sostenibles. Lógicamente la regulación del procedimiento concreto para determinar dichas cuestiones excede del concepto "bases del régimen jurídico de las Administraciones Públicas”, por lo que el legislador básico debería limitarse a enunciar los principios generales en la materia, dejando la concreción del procedimiento a la normativa de desarrollo.

Esta nueva regulación básica del régimen competencial de los municipios, tendente a fomentar la racionalidad y la eficiencia en la gestión del gasto público, debería girar, en mi opinión, en torno a los siguientes principios:

1.- Proclamación del principio de legalidad como vinculación positiva de la Administración al derecho, en el sentido de que toda actuación de la administración local debe estar expresamente habilitada por una norma legal.

2.- Concreción de la garantía institucional de la autonomía local en sentido positivo y negativo. En el primer aspecto se establecerán aquellas materias en las que los municipios deberán ostentar necesariamente competencias. En el segundo aspecto se determinarán aquellas materias en las que los municipios no podrán asumir competencias de ningún tipo.

3.- Habilitación de los municipios para actuar más allá de su ámbito competencial. La posibilidad de que los municipios actúen fuera del marco de sus competencias se insertará en el ámbito del principio de subsidiariedad, que, como manifestación del principio de universalidad, debería entenderse en el sentido de que el municipio podrá asumir — sin necesidad de título competencial específico- competencias en cualesquiera materias que, no estando incluidas en la delimitación negativa de la autonomía local, no estén atribuidas previamente a otros sujetos administrativos o estando no hayan sido puestas en funcionamiento por sus titulares.

4.- Diferenciación entre el ejercicio de servicios públicos de contenido no económico o funciones públicas y los servicios públicos de contenido económico o servicios públicos propiamente dichos.

Para la puesta en funcionamiento de cualquier servicio público de contenido económico será necesaria la tramitación de un procedimiento administrativo que garantice la economía, eficacia y eficiencia en la prestación del mismo, si bien el contendido de dicho expediente variará en función del tipo de servicio público de que se trate. Así se distinguiría entre servicios de prestación obligatoria y de prestación voluntaria, y tanto en una como en otra categoría habría que diferenciar entre los servicios que tienen un contenido perfectamente determinado (por ejemplo el abastecimiento domiciliario de agua potable) y aquellos otros cuyo contenido depende de la decisión del municipio (por ejemplo las instalaciones deportivas de uso público). De este modo: 
a) Servicios obligatorios de contenido predeterminado: el expediente únicamente tendrá por objeto la determinación de la forma de gestión más idónea para la prestación del servicio.

b) Servicios obligatorios de contenido variable: el expediente tendrá por objeto la determinación del alcance del servicio (en función de las necesidades realmente existentes en el municipio y de su disponibilidad económica) y la forma de gestión más idónea para su prestación.

c) Servicios no obligatorios de contenido predeterminado: en este caso el expediente deberá determinar la necesidad y conveniencia de la implantación del servicio, es decir que el servicio responde a una necesidad real de los vecinos y que el mismo es adecuado para atender dicha necesidad, así como la forma de gestión más idónea para la prestación del servicio y su sostenibilidad financiera.

d) Servicios no obligatorios de contenido variable: el expediente deberá determinar la necesidad y conveniencia de la implantación del servicio, determinar el contenido del mismo (en función de las necesidades realmente existentes en el municipio y de su disponibilidad económica) así como la forma de gestión más idónea para la prestación del servicio y su sostenibilidad financiera.

Dichos expedientes deberán tramitarse y resolverse en base a criterios técnicos objetivos, y el resultado de los mismos, en cuanto a la necesidad, oportunidad o conveniencia, contenido o alcance del servicio y sostenibilidad financiera del mismo, sería vinculante, pudiendo el Pleno Municipal, de forma motivada, alterar la forma de gestión del servicio propuesta.

5.- Responsabilidad. Por último, deberá establecerse un régimen de responsabilidad, rápido y eficaz que castigue de forma contundente a cualquiera, técnico o político, que por culpa o negligencia grave, contribuya a emplear el dinero público sin la racionalidad y eficiencia exigibles.

En mi opinión el legislador básico estaría plenamente habilitado para regular los anteriores aspectos, ya que los mismos no agotan la regulación de la materia, pudiendo encuadrarse perfectamente en el concepto de bases cuyo desarrollo corresponderá al legislador autonómico.

\section{BIBLIOGRAFÍA}

Ballesteros Fernández, Angel y Manuel (2005). Manual de Gestión de Servicios Públicos Locales. Madrid. El Consultor de los Ayuntamientos.

Boix Palop, Andrés (2014) "Sentido y orientación de la Ley 27/2013 de racionalización y sostenibilidad de la Administración local: autonomía local, recentralización y provisión de servicios públicos locales”. Revista de Estudios de la Administración Local y Autonómica (nueva época), número 2.

Calvo Bérguez, Juan (2014). "La nueva reforma de la Administración Local: principales cuestiones planteadas en el marco de su racionalización y sostenibilidad”. Revista de Estudios de la Administración Local y Autonómica (nueva época), número 2.

Del Guayo Castiella, Iñigo (2014). “Nuevo régimen jurídico de los servicios públicos locales, tras la Ley núm. 27/2013, de 27 de diciembre, de racionalización y sostenibilidad de la Administración Local”. Revista de Estudios de la Administración Local y Autonómica (nueva época), número 2.

Fernández Montalvo, Rafael (2011). "La doctrina del Tribunal Constitucional y la jurisprudencia del Tribunal Supremo sobre la provincia”. Cuadernos de Derecho Local, número 25, pp. 141-163.

Font i Llovet, Tomás (2007). “Autonomía Local y Estatutos: Crónica de un compromiso”. Anuario del Gobierno Local 2006. Fundación Democracia y Gobierno Local pp. 13-35.

García Roca, Javier (2000) “El concepto actual de autonomía local según el bloque de constitucionalidad”. Revista de Estudios de la Administración Local y Autonómica, número 282, pp 23-68.

García Roca, Javier (2007) "La primera sentencia constitucional sobre conflicto en defensa de la autonomía local (STC 240/2006): Una ocasión pérdida”. Cuadernos de Derecho Local, número 14, pp. 14/23.

Gracia Retortillo, Ricard (2000) “La autonomía local en Alemania a los dos siglos de su nacimiento: su posición jurídico-institucional”, Revista de Estudios de la Administración Local y Autonómica, número 282, pp. 11-46.

Ministerio de Hacienda y Administraciones Públicas. "Nota explicativa de la Reforma Local”, 5 de marzo de 2014 .

Navarro Rodríguez, Pilar y Zafra Victor, Manuel. (2014). “El pretendido blindaje autonómico de competencias municipales tras la reforma de la Administración Local”, Revista de Estudios de la Administración Local y Autonómica (nueva época), número 2. 
Núñez Rivero, Cayetano y García Aranda, Santiago (2013) “Las autonomía de los entes locales". Teoría y realidad constitucional (UNED), número 31, pp. 401-438.

Ortega Alvarez, Luís (1989). "El respeto del ámbito de la autonomía local por el legislador autonómico de navarra". Revista Jurídica de Navarra, número 7, pp. 33-46.

Parejo Alfonso, Luciano (2008). "La autonomía local desde el punto de vista de su realización efectiva”. Revista electrónica CEMCl, número 1, pp. 1-37.

Pomed Sánchez, Luís. "Jurisprudencia constitucional sobre administración local. Primera sentencia dictada en un conflicto en defensa de la autonomía local”. Anuario del Gobierno Local 2006. Fundación Democracia y Gobierno Local pp-233-257.

Varios autores. "Libro Blanco para la reforma del Gobierno Local". 2005. Madrid, Ministerio de Administraciones Públicas, Secretaría General Técnica. 
